\title{
The impact of caspase-12 on susceptibility to candidemia
}

\author{
D. C. Rosentul • T. S. Plantinga - W. K. Scott • \\ B. D. Alexander • N. M. D. van de Geer • J. R. Perfect • \\ B. J. Kullberg • M. D. Johnson • M. G. Netea
}

Received: 9 February 2011 / Accepted: 24 May 2011 /Published online: 25 June 2011

(C) The Author(s) 2011. This article is published with open access at Springerlink.com

\begin{abstract}
Candida is one of the leading causes of sepsis, and an effective host immune response to Candida critically depends on the cytokines IL-1 $\beta$ and IL-18, which need caspase-1 cleavage to become bioactive. Caspase- 12 has been suggested to inhibit caspase- 1 activation and has been implicated as a susceptibility factor for bacterial sepsis. In populations of African descent, CASPASE-12 is either functional or non-functional. Here, we have assessed the frequencies of both CASPASE-12 alleles in an AfricanAmerican Candida sepsis patients cohort compared to
\end{abstract}

D. C. Rosentul - T. S. Plantinga $(\bowtie) \cdot$ N. M. D. van de Geer

B. J. Kullberg • M. G. Netea

Department of Medicine,

Radboud University Nijmegen Medical Centre,

Internal postal code 463, P.O. Box 9101, Geert Grooteplein 8,

6500 HB Nijmegen, The Netherlands

e-mail: t.plantinga@aig.umcn.nl

D. C. Rosentul - T. S. Plantinga • N. M. D. van de Geer •

B. J. Kullberg • M. G. Netea

Nijmegen Institute for Infection,

Inflammation and Immunity (N4i), Radboud University Nijmegen

Medical Centre,

P.O. Box 9101, 6500 HB Nijmegen, The Netherlands

W. K. Scott

Dr. John T. Macdonald Foundation Department of Human Genetics and John P. Hussman Institute for Human Genomics, University of Miami, Miller School of Medicine,

Miami, FL 33136, USA

B. D. Alexander $\cdot$ J. R. Perfect $\cdot$ M. D. Johnson

Duke University Medical Centre,

Durham, NC 27708, USA

M. D. Johnson

Department of Clinical Research,

Campbell University School of Pharmacy,

Buies Creek, NC 27506, USA uninfected patients with similar predisposing factors. African-American Candida sepsis patients $(n=93)$ and non-infected African-American patients $(n=88)$ were genotyped for the CASPASE-12 genotype. Serum cytokine concentrations of IL-6, IL-8, and IFN $\gamma$ were measured in the serum of infected patients. Statistical comparisons were performed in order to assess the effect of the CASPASE-12 genotype on susceptibility to candidemia and on serum cytokine concentrations. Our findings demonstrate that CASPASE-12 does not influence the susceptibility to Candida sepsis, nor has any effect on the serum cytokine concentrations in Candida sepsis patients during the course of infection. Although the functional CASPASE-12 allele has been suggested to increase susceptibility to bacterial sepsis, this could not be confirmed in our larger cohort of fungal sepsis patients.

\section{Introduction}

One of the leading pathogens causing sepsis in immunocompromised hosts are Candida spp. [1, 2]. Medical conditions that lead to an immunocompromised state increase susceptibility to Candida sepsis [3]. In addition to exogenous factors, it is believed that genetic variation also plays an important role in susceptibility to sepsis [46]. Caspase- 12 is an inflammatory caspase, in which a lossof-function genetic variant has been fixed in some populations by still undefined evolutionary pressures $[7-$ 9]. This loss-of-function is due to the presence of a $\mathrm{T} / \mathrm{C}$ single nucleotide polymorphism (rs497116) on nucleotide position 125 in the CASPASE-12 gene [10]. Although the ancestral variant is still present in African and AfricanAmerican populations, of which $20-30 \%$ express the active 
variant of caspase-12, it is absent in Asian and Caucasian populations $[9,10]$.

Functional studies have suggested that functional caspase-12 is a negative regulator of caspase-1 activation, which might result in less cytokine production in response to recognition through pattern recognition receptors. Thus, based on the proposed inhibitory effect on caspase-1 and, consequently, lower IL-1 $\beta$ and IL-18 production, functional caspase-12 may increase the susceptibility to severe sepsis and/or the clinical outcome of sepsis patients [10]. Therefore, it is compelling to assess whether genetic variation in CASPASE-12 plays a role in the susceptibility to Candida sepsis. The aim of this study was to assess whether genetic variants of CASPASE-12 influence the incidence, severity, and mortality of Candida sepsis in a cohort of African-American patients.

\section{Patients, materials, and methods}

Subjects were enrolled between January 2003 and January 2009 after informed consent (or waiver, as approved by the Institutional Review Board) at the Duke University Hospital (DUMC, Durham, NC, USA). Infected subjects had $\geq 1$ positive blood cultures for a Candida species while hospitalized. Non-infected controls were recruited from the same hospital wards as infected patients, with no history or evidence of Candida sepsis/invasive candidiasis or any invasive fungal infection.

Genomic DNA was isolated from whole blood using standard procedures. The region of interest of the $C A S$ PASE-12 gene was amplified as described previously [10].

Circulating cytokine concentrations of IL-6, IL-8, and IFN $\gamma$ in infected patients were measured by Multiplex Fluorescent Bead Immunoassays (xMAP technology, BioRad, Veenendaal, the Netherlands), from day 0 up to day 5 after the initial positive blood culture.

Statistical comparisons of frequencies were made between infected versus non-infected subjects using Chi-square tests. Statistical analysis of the cytokine data was performed by using the Mann-Whitney $U$-test. Overall, a $p$-value $<0.05$ was considered to be statistically significant.

\section{Results}

A total of 93 African-American patients and 88 noninfected African-American controls had genetic and clinical data available for the analysis. The demographic data for the study subjects are presented in Table 1.

No significant differences in the distribution of $C A S$ PASE-12 genotypes were seen when comparing infected
Table 1 Baseline patient characteristics of African-American patients with Candida systemic infection or uninfected controls recruited at the Duke University Hospital (DUMC, Durham, NC, USA) $(n=181)$

\begin{tabular}{|c|c|c|}
\hline Variable & $\begin{array}{l}\text { Infected } \\
\text { cohort } \\
(n=93), \%\end{array}$ & $\begin{array}{l}\text { Control } \\
\text { cohort } \\
(n=88), \%\end{array}$ \\
\hline Mean age (years) & 52 & 52 \\
\hline \multicolumn{3}{|l|}{ Gender } \\
\hline Male & 51.6 & 48.9 \\
\hline Family & 48.4 & 51.1 \\
\hline Immunocompromised state & 54.8 & 48.9 \\
\hline $\mathrm{HSCT}$ & 0 & 0 \\
\hline Solid organ transplant & 7.5 & 3.5 \\
\hline Active malignancy* & 22.6 & 13.8 \\
\hline Solid tumor & 14 & 8.0 \\
\hline Leukemia & 5.4 & 3.5 \\
\hline Lymphoma & 3.2 & 2.3 \\
\hline Chemotherapy within past 3 months & 12.9 & 5.6 \\
\hline Neutropenia (ANC $<500$ cells $/ \mathrm{mm}^{3}$ ) & 4.3 & 1.2 \\
\hline HIV-infected & 5.4 & 0 \\
\hline Surgery within past 30 days & 34.4 & 30.7 \\
\hline Receipt of total parenteral nutrition & 19.4 & 5.75 \\
\hline Dialysis-dependent & 15.1 & 8.0 \\
\hline Acute renal failure & 36.6 & 33.0 \\
\hline Liver failure & 25.8 & 1.2 \\
\hline $\begin{array}{l}\text { Intensive care unit admission within the } \\
\text { past } 14 \text { days }\end{array}$ & 39.8 & 31.8 \\
\hline Median baseline serum creatinine $(\mathrm{mg} / \mathrm{dL})$ & 2.27 & 1.9 \\
\hline Median baseline WBC count (cells $/ \mathrm{mm}^{3}$ ) & 13.0 & 10.87 \\
\hline \multicolumn{3}{|l|}{ Candida spp.** } \\
\hline albicans & 44.2 & - \\
\hline glabrata & 23.7 & \\
\hline parapsilosis & 17.2 & \\
\hline tropicalis & 10.8 & \\
\hline krusei & 3.2 & \\
\hline Other Candida spp. & 0.9 & \\
\hline
\end{tabular}

* Subjects could have more than one active malignancy

**Sixteen subjects had $>1$ species isolated

patients (CC 3.9\%, CT 25.3\%, TT 72.4\%) and non-infected controls (CC $2.9 \%$, CT $30.0 \%$, TT $66.1 \%)(p>0.05)$. No associations between the CASPASE-12 genotypes and disseminated disease, persistent fungemia, or 30-day mortality were observed (data not shown).

Serum samples collected from infected patients during the first 5 days after the initial positive blood culture were measured for concentrations of IL-6, IL-8, and IFN $\gamma$. Also, measurements of IL- $1 \beta$ and IL-18 were performed in these samples. However, the concentrations of these cytokines were too low to detect (data not shown). Cytokine concentrations decreased over time. No differences in 

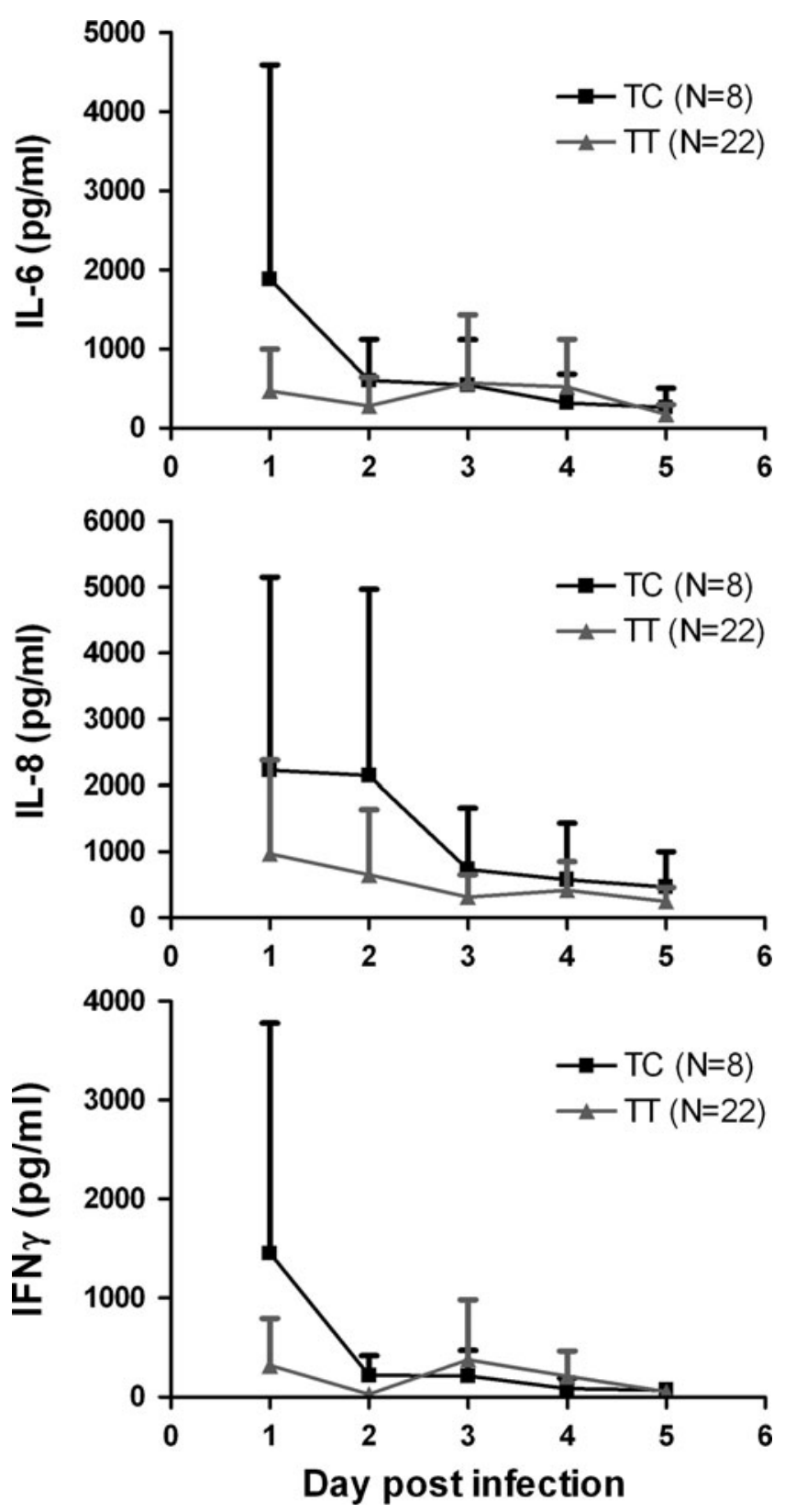

Fig. 1 IL-6, IL-8, and IFN $\gamma$ circulating concentrations in infected patients from day 0 up to day 5 after initial positive blood culture, in relation to the CASPASE-12 genotype. TC heterozygous, TT homozygous mutant. The data are presented as mean \pm standard error of the mean (SEM)

cytokine concentrations were apparent between individuals bearing different CASPASE-12 genotypes (Fig. 1).

\section{Discussion}

Caspase-12 has been suggested to inhibit caspase-1 processing of proIL-1 $\beta$ and proIL-18 into the active cytokines.
Genetic variation of CASPASE-12 in populations of African descent has been previously associated with susceptibility to bacterial sepsis [10]. The present study was performed in order to assess the role of caspase-12 in sepsis caused by Candida spp. The results indicate that the CASPASE-12 genotype has no significant effect on the susceptibility and severity of systemic infections with Candida.

Candida is one of the leading pathogens causing sepsis $[2,11,12]$. Pro-inflammatory cytokines such as IL-1 $\beta$ and IL-18 are a crucial factor in eliciting an effective immune response to eradicate the infection. A modulatory step in the production of these cytokines is exerted at the level of caspase-1, a protease that cleaves the pro-form of these cytokines into shorter bioactive proteins [13, 14]. It has previously been reported that CASPASE-12 knockout mice were better capable of clearing both local and systemic bacterial infections compared to wild-type mice, through an improved inflammatory response [15]. The same authors described a similar effect of caspase- 12 in patients with bacterial sepsis, with individuals bearing functional caspase-12 being more susceptible to this condition [10]. However, the role of CASPASE-12 genetic variants in fungal sepsis has not been addressed so far.

Firstly, the comparison of CASPASE-12 genotype frequencies in African-American patients with non-infected controls revealed no statistically significant differences. Secondly, no effects of the CASPASE-12 genotype was observed in relation to the clinical outcome of infection, assessed as disseminated disease, persistent fungemia, and 30-day mortality. Furthermore, serum cytokine concentrations during the first 5 days of infection were shown to be unaffected by the CASPASE-12 genotype.

Our findings on the lack of influence of the CASPASE-12 genotype on fungal sepsis contrast with those of Saleh et al. $[10,15]$, who suggested an important role of this genetic variant in bacterial sepsis. Moreover, circulating cytokine concentrations in infected patients were also not influenced by the CASPASE-12 genotype. It should be emphasized that this is, in particular, true for IL-6 and IFN $\gamma$, cytokines that are induced by IL-1 $\beta$ and IL-18, respectively [16-18]. This provides indirect evidence that functional caspase-12 has no clear effect on the production of IL-1 $\beta$ and IL-18 in the context of Candida sepsis. One possible explanation for the discrepancy between this study and that of Saleh et al. [10] is represented by the different cause of sepsis in the two studies, fungal and bacterial, respectively. However, one has to concede that the pro-inflammatory cytokines, of which production is reportedly regulated by the CASPASE-12 genotype, exert similar protective effects in bacterial and fungal sepsis [18-21]. In this respect, a recent study has also failed to reproduce the inhibitory effects of the CASPASE-12 genotype of lipopolysaccharide and Gram- 
negative bacteria-induced cytokine production [22], bringing into question the biological activity of caspase- 12 .

In conclusion, although an effect of the CASPASE-12 genotype on the susceptibility to bacterial sepsis has been previously reported in a small cohort of African-American patients [10], this could not be confirmed in our larger cohort of fungal sepsis patients. Furthermore, clinical outcome and in vivo cytokine responses were not influence by the CASPASE-12 genotype. Therefore, we propose that caspase-12 is redundant for systemic host defense in sepsis.

Acknowledgments D.C.R. was funded by the European Commission through the FINSysB Marie Curie Initial Training Network (PITN-GA2008-214004). This study was partially supported by a Vici grant from the Netherlands Organisation for Scientific Research (NWO) to M.G.N., and NIH grants AI-51537 to M.D.J. and AI-73896 to J.R.P.

Conflict of interest All authors declare no conflicts of interest.

Open Access This article is distributed under the terms of the Creative Commons Attribution Noncommercial License which permits any noncommercial use, distribution, and reproduction in any medium, provided the original author(s) and source are credited.

\section{References}

1. Pfaller MA, Diekema DJ (2007) Epidemiology of invasive candidiasis: a persistent public health problem. Clin Microbiol Rev 20:133-163

2. Gudlaugsson O, Gillespie S, Lee K, Vande Berg J, Hu J, Messer S, Herwaldt L, Pfaller M, Diekema D (2003) Attributable mortality of nosocomial candidemia, revisited. Clin Infect Dis 37:1172-1177

3. Eggimann P, Garbino J, Pittet D (2003) Epidemiology of Candida species infections in critically ill non-immunosuppressed patients. Lancet Infect Dis 3:685-702

4. Khor CC, Chapman SJ, Vannberg FO, Dunne A, Murphy C, Ling EY, Frodsham AJ, Walley AJ, Kyrieleis O, Khan A, Aucan C, Segal S, Moore CE, Knox K, Campbell SJ, Lienhardt C, Scott A, Aaby P, Sow OY, Grignani RT, Sillah J, Sirugo G, Peshu N, Williams TN, Maitland K, Davies RJ, Kwiatkowski DP, Day NP, Yala D, Crook DW, Marsh K, Berkley JA, O'Neill LA, Hill AV (2007) A Mal functional variant is associated with protection against invasive pneumococcal disease, bacteremia, malaria and tuberculosis. Nat Genet 39:523-528

5. Lorenz E, Mira JP, Frees KL, Schwartz DA (2002) Relevance of mutations in the TLR4 receptor in patients with gram-negative septic shock. Arch Intern Med 162:1028-1032

6. Sutherland AM, Walley KR, Russell JA (2005) Polymorphisms in CD14, mannose-binding lectin, and Toll-like receptor-2 are associated with increased prevalence of infection in critically ill adults. Crit Care Med 33:638-644

7. Eckhart L, Ballaun C, Hermann M, VandeBerg JL, Sipos W, Uthman A, Fischer H, Tschachler E (2008) Identification of novel mammalian caspases reveals an important role of gene loss in shaping the human caspase repertoire. Mol Biol Evol 25:831-841
8. Yngvadottir B, Xue Y, Searle S, Hunt S, Delgado M, Morrison J, Whittaker P, Deloukas P, Tyler-Smith C (2009) A genome-wide survey of the prevalence and evolutionary forces acting on human nonsense SNPs. Am J Hum Genet 84:224-234

9. Xue Y, Daly A, Yngvadottir B, Liu M, Coop G, Kim Y, Sabeti P, Chen Y, Stalker J, Huckle E, Burton J, Leonard S, Rogers J, TylerSmith C (2006) Spread of an inactive form of caspase-12 in humans is due to recent positive selection. Am J Hum Genet 78:659-670

10. Saleh M, Vaillancourt JP, Graham RK, Huyck M, Srinivasula SM, Alnemri ES, Steinberg MH, Nolan V, Baldwin CT, Hotchkiss RS, Buchman TG, Zehnbauer BA, Hayden MR, Farrer LA, Roy S, Nicholson DW (2004) Differential modulation of endotoxin responsiveness by human caspase-12 polymorphisms. Nature 429:75-79

11. Martin GS, Mannino DM, Eaton S, Moss M (2003) The epidemiology of sepsis in the United States from 1979 through 2000. N Engl J Med 348:1546-1554

12. Wisplinghoff H, Bischoff T, Tallent SM, Seifert H, Wenzel RP, Edmond MB (2004) Nosocomial bloodstream infections in US hospitals: analysis of 24,179 cases from a prospective nationwide surveillance study. Clin Infect Dis 39:309-317

13. Martinon F, Tschopp J (2004) Inflammatory caspases: linking an intracellular innate immune system to autoinflammatory diseases. Cell 117:561-574

14. Fantuzzi G, Dinarello CA (1999) Interleukin-18 and interleukin-1 beta: two cytokine substrates for ICE (caspase-1). J Clin Immunol 19:1-11

15. Saleh M, Mathison JC, Wolinski MK, Bensinger SJ, Fitzgerald P, Droin N, Ulevitch RJ, Green DR, Nicholson DW (2006) Enhanced bacterial clearance and sepsis resistance in caspase-12deficient mice. Nature 440:1064-1068

16. Tosato G, Jones KD (1990) Interleukin-1 induces interleukin-6 production in peripheral blood monocytes. Blood 75:13051310

17. Zhang YH, Lin JX, Vilcek J (1990) Interleukin-6 induction by tumor necrosis factor and interleukin-1 in human fibroblasts involves activation of a nuclear factor binding to a kappa B-like sequence. Mol Cell Biol 10:3818-3823

18. Netea MG, Stuyt RJ, Kim SH, Van der Meer JW, Kullberg BJ, Dinarello CA (2002) The role of endogenous interleukin (IL)-18, IL-12, IL-1beta, and tumor necrosis factor-alpha in the production of interferon-gamma induced by Candida albicans in human whole-blood cultures. J Infect Dis 185:963-970

19. Mencacci A, Bacci A, Cenci E, Montagnoli C, Fiorucci S, Casagrande A, Flavell RA, Bistoni F, Romani L (2000) Interleukin 18 restores defective Th1 immunity to Candida albicans in caspase 1-deficient mice. Infect Immun 68:5126-5131

20. Hultgren OH, Svensson L, Tarkowski A (2002) Critical role of signaling through IL-1 receptor for development of arthritis and sepsis during Staphylococcus aureus infection. J Immunol 168:5207-5212

21. Bohn E, Sing A, Zumbihl R, Bielfeldt C, Okamura H, Kurimoto M, Heesemann J, Autenrieth IB (1998) IL-18 (IFN-gammainducing factor) regulates early cytokine production in, and promotes resolution of, bacterial infection in mice. J Immunol 160:299-307

22. Ferwerda B, McCall MB, de Vries MC, Hopman J, Maiga B, Dolo A, Doumbo O, Daou M, de Jong D, Joosten LA, Tissingh RA, Reubsaet FA, Sauerwein R, van der Meer JW, van der Ven AJ, Netea MG (2009) Caspase-12 and the inflammatory response to Yersinia pestis. PLoS One 4:e6870 